\title{
Detection Via Laser Desorption and Mass Spectrometry of Multiplex Electrophore-labeled Albumin
}

\author{
Nanying Bian', Poguang Wang ${ }^{2}$, Zhixian Wang', Linxiao Xu1,2, George Church' and Roger W. \\ Giese $^{1 *}$ \\ ${ }^{1}$ Department of Pharmaceutical Sciences in the Bouvé College of Pharmacy and Health Professions, Barnett Institute, \\ and Chemistry Department, Northeastern University, Boston, MA 02115, USA \\ ${ }^{2}$ Department of Genetics, Howard Hughes Medical Institute at Harvard Medical School, Boston, MA 02115, USA
}

SPONSOR REFEREE: Professor Catherine E. Costello, Boston University School of Medicine, BOSTON, MA 02118, USA

\begin{abstract}
Albumin was reacted with a mixture of six electrophore $N$-hydroxysuccinimide esters, each of which possessed an interior glycolketo linkage. The purpose of this linkage is to release the attached electrophore as a ketone when heated, due to a thermal retro-aldol reaction. The multiplex electrophore-labeled albumin was detected as a dried spot deposited on a polyimide membrane by laser desorption/capillary collection (of the released ketone electrophores)/off-line gas chromatography/electron capture-mass spectrometry. This encourages further study of such electrophore labels in immunoassays and related techniques, where there is a need to make advances in multi-analyte detection. (C) 1997 John Wiley \& Sons, Ltd.
\end{abstract}

Received 5 September 1997; Accepted 8 September 1997

Rapid. Commun. Mass Spectrom. 11, 1781-1784 (1997)

No. of Figures: 3 No. of Tables: 0 No. of Refs: 14

'Multi-analyte detection', the detection of multiple analytes in a given sample simultaneously (or essentially so), can be advantageous in several respects. Depending on how it is accomplished, it can improve sample throughput, reduce the amount of sample required, and, via the use of internal standards, improve accuracy and precision. Thus, there is great interest in multi-analyte detection in several areas (with some overlap) such as immunoassays, ${ }^{1,2}$ combinatorial synthesis, ${ }^{3-5}$ drug analysis ${ }^{6}$ and DNA sequencing. ${ }^{7}$

Mass spectrometry is relevant to multi-analyte detection in two ways: direct detection of multiple analytes, and detection of multiple molecular labels that are either attached to analytes or to molecules involved in a ligand assay for the analytes. For example, metal ions are being studied as multiplexed labels for detection by MS. ${ }^{8,9}$

We are developing electrophores as multiplexed labels which can be detected by electron capture mass spectrometry (EC-MS). ${ }^{10,11}$ In this report we demonstrate the detection of six electrophores on electrophore-multiplexed albumin by the following sequence of steps: (1) thermal release of the electrophores by $\mathrm{CO}_{2}$ laser desorption, (2) collection into a vacuum capillary, and (3) rinsing out the capillary with solvent and injection into a GC/EC-MS.

\footnotetext{
*Correspondence to: R.W. Giese, Department of Pharmaceutical Sciences in the Bouvé College of Pharmacy and Health Professions, Barnett Institute and Chemistry Department, Northeastern University, Boston, MA 02115, USA

Contract grant sponsor: NIST; Contract grant number: 70NANB5H1038

Contract grant sponsor: NIH; Contract grant number: HG00029

Contract grant sponsor: DOE; Contract grant number:

DE-FG02-87ER60565
}

\section{EXPERIMENTAL}

\section{Materials}

Bovine serum albumin (B2518; less than 2\% acetylated) and 2,4,6-trinitrobenzene sulfonic acid (TNBS) were obtained from Sigma (St. Louis, MO, USA). Electrophores 1, 2, 3 and $\mathbf{6}$ were synthesized as described, ${ }^{11}$ and $\mathbf{4}$ and $\mathbf{5}$ were prepared similarly. Kapton type HN polyimide membrane was from Dupont (Circleville, OH, USA).

\section{Electrophore-multiplexed albumin}

Albumin labeling. Albumin (2 $\mathrm{mg}$ ) was dissolved in 1 $\mathrm{mL}$ of $0.1 \mathrm{~m}$ potassium phosphate, $\mathrm{pH} 8.0$, and a solution of the 1-6 (ca. $2 \mathrm{mg}$ each) in $2 \mathrm{~mL}$ acetonitrile was added. After 5 min of vortexing and then standing at room temperature for $24 \mathrm{~h}$, the sample was dialyzed against $7 \times 2$ liter of the corresponding $0.01 \mathrm{~m}$ buffer at room temperature for two days, followed by gel filtration on a Sephadex PD-10 column (Pharmacia, Uppsala, Sweden). The amount of albumin recovered was determined using a Total Protein kit (690-A, Sigma) and the number of residual free amino groups remaining was measured using $\mathrm{TNBS}^{12}$ based on calibration with albumin in each case.

\section{Laser desorption}

A $\mu$-TEA $\mathrm{CO}_{2}$ laser (Laser Science, Inc., Newton, MA) with a pulse energy of $7 \mathrm{~mJ}$ and a pulse width of $500 \mathrm{~ns}$ at $1 \sim 20 \mathrm{~Hz}$ was used. The electrophore-protein (260 $\mathrm{ng}$ ) in $0.5 \mu \mathrm{L}$ water was deposited onto the center of a $25 \mu \mathrm{m}$ thick polyimide membrane $\left(1 \times 1.5 \mathrm{~cm}^{2}\right)$, to give a spot with a diameter of about $2 \mathrm{~mm}$ (front side by definition). The $\mathrm{CO}_{2}$ laser beam was focused to a zone of about $200 \times 300 \mu^{2}$ within the sample spot onto the back side of the membrane. After a single laser pulse was applied, a cooled (acetone/dry ice) collection 
capillary under vacuum on the front side $(2 \mathrm{~mm}$ from the membrane surface), which collected some of the plume of electrophores, was rinsed with $20 \mu \mathrm{L}$ of ethyl acetate, and $1 \mu \mathrm{L}$ was injected into a GC/EC-MS (Hewlett Packard 5988A MS coupled to a HP 5890 GC fitted with an Hewlett Packard Ultra-2 HP capillary column, $25 \mathrm{~m} \times 0.32 \mathrm{~mm}$ i.d., $0.17 \mu \mathrm{m}$ film thickness; Wilmington, DE, USA).

\section{RESULTS AND DISCUSSION}

The structures of the six electrophore $N$-hydroxysuccinimide esters employed in this study are shown in Fig. 1. The purpose of the $p$-methoxy group in compounds $\mathbf{1}$ and $\mathbf{3}$ is to stabilize this site on the tetrafluorobenzyl moiety against chemical substitution during synthesis, since a fluorine atom at this position tends to undergo nucleophilic substitution. In

Electrophore NHS ester

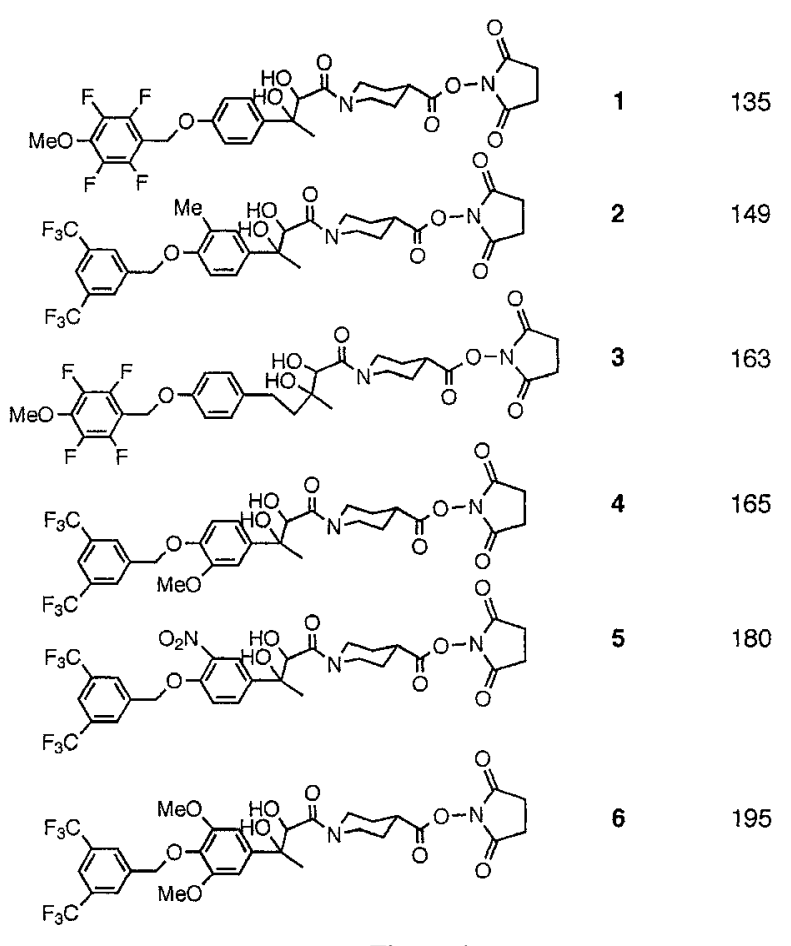

Figure 1. compounds $\mathbf{2}, \mathbf{4 ,} 5$ and $\mathbf{6}$, this complication is avoided by employing a bis-trifluoromethyl-benzyl moiety. The other structural variations in the compounds are present to create different masses for the ions that are ultimately formed and detected as discussed below. Previously we demonstrated that electrophores such as these give electron capture mass spectra in which there is just one major peak along with the isotope peak and one or two minor peaks. ${ }^{11}$

Albumin as a model protein was modified with a mixture of compounds 1-6. Assay of the albumin before and after this modification revealed that $76 \%$ of the primary amino groups (61 total) on the protein were labeled. This total labeling was reproducible $(79 \%$ in a second experiment). In spite of this significant degree of labeling, the albumin remained fully soluble throughout the procedure, reflecting in part the moderate polarity (as designed) of our electrophore labels. A control experiment in which albumin was similarly exposed to the carboxylic acid precursors of compounds 1-6 demonstrated that $<2 \%$ of these precursor compounds were co-recovered with the albumin at the end of the procedure.

Laser desoprtion of the multiplex electrophorelabeled albumin was performed according to the drawing shown in Fig. 2. The purpose of the heliumneon laser was to provide a visible beam to monitor the location of the beam from the $\mathrm{CO}_{2}$ laser. A droplet of the electrophore albumin was evaporated onto polyimide membrane (front side) followed by application of a single pulse of radiation from the $\mathrm{CO}_{2}$ laser to the back side. The $\mathrm{CO}_{2}$ laser beam was focused with a $\mathrm{ZnSe}$ lens to give an energy density $5 \mathrm{~J} / \mathrm{cm}^{2}$. Based on the fact that a $25 \mu \mathrm{m}$ thick polyimide membrane has an absorbance of 0.35 at $10.6 \mu \mathrm{m}$, we calculated that the temperature on the front side of the $25 \mu \mathrm{m}$ thick polyimide membrane within the heated zone should have risen to about $500{ }^{\circ} \mathrm{C} .{ }^{13}$ Since the electrophores possess a $\beta$-hydroxyketo linkage that can undergo a thermal retro-aldol reaction to form a ketone at the $\beta$-hydroxy site, the laser desorption thereby releases tetrafluoromethoxybenzyloxy- or bis-trifluoromethylbenzyloxy acetophenone-like products. We anticipated $500{ }^{\circ} \mathrm{C}$ would be sufficient to release the ketones for two reasons. First of all, such ketones are observed when compounds similar to 1-6 are injected into a gas

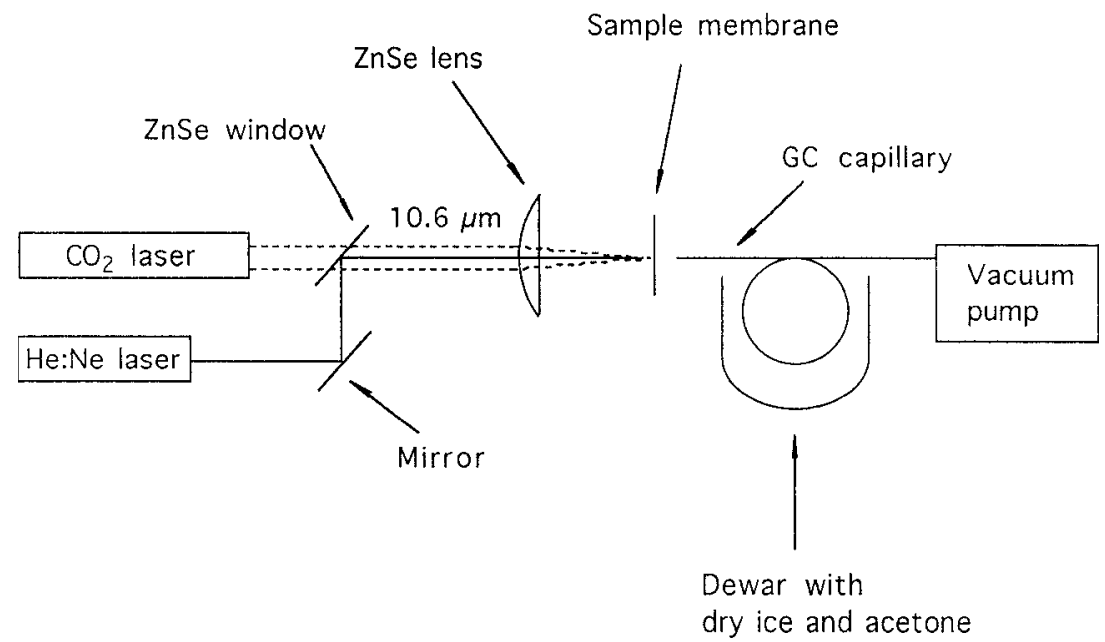

Figure 2. 
chromatograph fitted with an injector heated at $300{ }^{\circ} \mathrm{C}$, and the yield was $95 \%$ for one tested quantitatively. ${ }^{11}$ Secondly, $\beta$-hydroxyketones are known to undergo a thermal retro-aldol reaction on a millisecond time scale at this temperature. ${ }^{14}$

As shown in Fig. 2, a cold capillary under vacuum is positioned to trap at least some of the plume of laserdesorbed ketone electrophores. For a ketone electrophore deposited on the membrane, the collection efficiency was found to be $10 \%$ without any effort at optimization. After the desorption, the capillary was rinsed with ethyl acetate. Injection of this latter solution into a GC/EC-MS gave the mass chromatograms shown in Fig. 3. Six ion channels were monitored, one for each of the acetylphenolate-like ions anticipated from com- pounds 1-6. Because the electrophore derived from compound 2 gives a fragment at $\mathrm{m} / \mathrm{z} 135$ with a $1 \%$ relative abundance, a peak at this position is seen in the $\mathrm{m} / \mathrm{z} 135$ chromatogram along with one for the electrophore formed from compound 1. All of the ketone electrophores give a similar electron capture response (within a factor of 2). Thus the variation in ion intensity among the six chromatograms arises in part from other factors such as differences in the reactivity of the albumin with compounds 1-6. The same pattern of peak intensities was observed for both preparations of electrophore-labeled albumin.

The good signal-to-noise ratio that we have obtained in this experiment encourages further testing along these lines. Ultimately our goal is to measure the plume
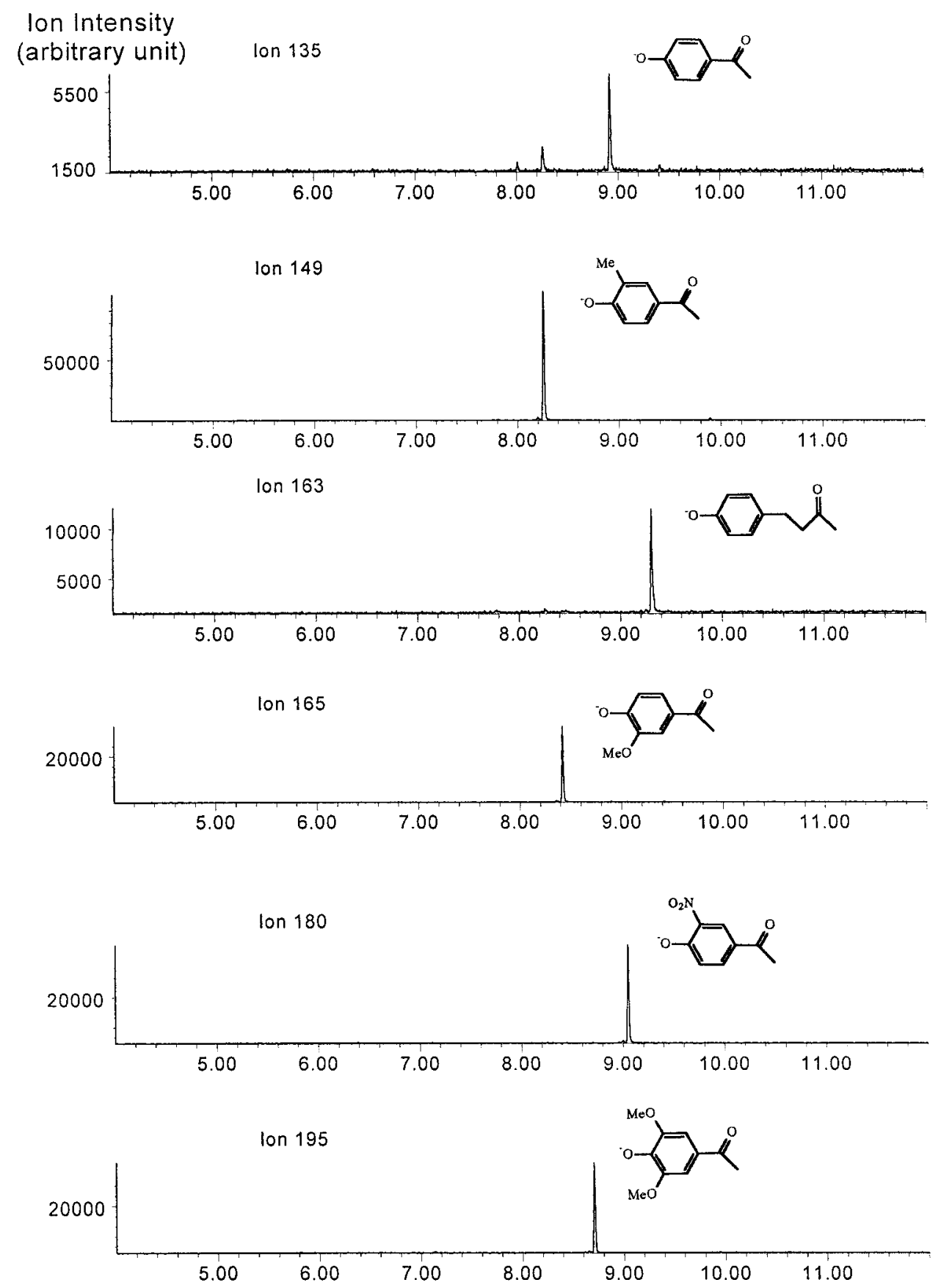

GC Retention Time (min.)

Figure 3. 
of ketone electrophores directly by electron capture time-of-flight mass spectrometry. This may be a more difficult challenge in terms of noise, since there will be no intervening collection capillary or GC separation to purify the electrophores prior to such detection.

\section{Acknowledgement}

This work was supported by NIST award 70NANB5H1038, NIH Grant HG00029, and DOE Grant DE-FG02-87ER60565. Contribution No. 725 from the Barnett Institute.

\section{REFERENCES}

1. L. J. Kricka, Clin. Chem. 38, 327 (1992).

2. E. R. Hendrickson, T. M. Hatfield Truby, R. D. Joerger, W. R. Majarian and R. C. Ebersole, Nucl. Acids Res. 23, 522 (1995).

3. J. A. Ellman, Acc. Chem. Res. 29, 132 (1996).

4. F. Balkenhohl, C. von dem Bussche-Hünnefeld, A. Lansky and C. Zechel, Angew. Chem. Int. Ed. Engl. 35, 2288 (1996).
5. M. H. J. Ohlmeyer, R. N. Swanson, L. W. Dillard, J. C. Reader, G. Asouline, R. Kobayashi, M. Wigler and W. C. Clark, Proc. Natl. Acad. Sci. USA 90, 10922 (1993).

6. K. F. Buechler, S. Moi, B. Noar, D. McGrath, J. Villela, M. Clancy, A. Shenhav, A. Colleymore, G. Valkirs, T. Lee, J. F. Bruni, M Walsh, R. Hoffman, F. Ahmuty, M. Nowakowski, J. Buechler, M. Mitchell, D. Boyd, N. Stiso and R. Anderson, Clin. Chem. 38, 1678 (1992).

7. P. Richterich and G. M. Church, Methods in Enzymol. 218, 187 (1993).

8. T. Sano, A. N. Glazer and C. R. Cantor, Proc. Natl. Acad. Sci. USA 89, 1534 (1992).

9. H. F. Arlinghaus, M. N. Kwoka, X-Q. Guo and K. B. Jacobson, Anal. Chem. 69, 1510 (1997).

10. L. Xu, D. Magiera, H. Abushamaa, S. Kugabalasooriar and R. Giese, J. Chromatogr. 764, 95 (1997).

11. L. Xu, N. Bian, Z. Wang, S. Abdel-Baky, S. Pillai, D. Magiera, V. Murugaiah, R. W. Giese, P. Wang, T. O'Keeffe, H. Abushamaa, L. Kutney, G. Church, S. Carson, D. Smith, M. Park, J. Wronka and F. Laukien, Anal. Chem. 69, 3595 (1997).

12. L. C. Mokrasch, Anal. Biochem. 18, 64 (1967).

13. P. Wang, G. Church, R. Giese and L. Khundkar, in preparation.

14. W. Feng, Y. Wang and S. Zhang, Int. J. Quantum Chem. 62, 297 (1997). 